\title{
Analysis on situation and strategy of Chinese Shipbuilding Industry Development
}

\author{
Liuping Chen \\ Research Institute of Machinery Industry Economic Management, No.397-A, out of Guang'anmen \\ Street, Xicheng District, Beijing City, China \\ chnclp@vip.163.com
}

Keywords: Shipbuilding Industry; Development Character; Problem; Development Strategy

\begin{abstract}
These development characters of Chinese Shipbuilding Industry including the speeding up the adjustment and upgrading of industrial structure and the Strengthening the technology innovation, are firstly summarized. Secondly these development problems of Chinese Shipbuilding Industry including the falling competitive power of the whole industry and the lower Industrial Center Radio are pointed out. Finally the development strategies including further speeding up the adjustment and upgrading of industrial structure and paying close attention to the adjustment and development of the medium-sized and small enterprises are put forwarding.
\end{abstract}

\section{Introduction}

In recent years, Chinese Shipbuilding Industry (SI) insists on optimizing industrial structure and accelerating technical innovation and then accomplishes the achievements that the number of the annual orders accepted is the most one in the world and that China-Japan-South Korea becomes the situation of tripartite confrontation in the global SI on the base of making full use of the advantage of the labor resource and the raw material since 2011. However Chinese SI still has some problems and in a whole hasn' t a piece of good performance in the economical operation because of the deep influence caused by the international financial crisis. View of this, the development strategy will be put forward based on analysis of the development characters and the problem of Chinese SI.

\section{Development Character ${ }^{[1,2]}$}

Overall, Chinese SI has the following characters.

Speed up Adjustment and Upgrading of Industrial Structure. On the premise of careful studying and carrying out the related polices made by the State Council and related ministries, Chinese SI proceed from the industrial reality to in a whole speed up the adjustment and upgrading of industrial structure by many means such as active relying on innovation-driven, optimizing the industrial structure, promoting the transformation and upgrading, strictly control new capacity and so on.

Strengthen Technology Innovation. In recent years, key enterprises and research institutions unceasingly strengthen the development of green environmental protection mainstream ships, and accelerate the $R \& D$ of the high-tech equipment and the marine engineering equipment, and have made a series of new progress and new break through. According to an incomplete statistics, in recent years, hundreds of new types of green environmental protection ships have been produced, and many special ships and high-tech ships, which includes the large-scale Liquefied Natural Gas (LNG) ship, the large Liquefied Gas Carriers (VLGC), the super large series of container ship, the vehicle Ro-Ro Carrier, the dual phase stainless steel chemical ship, the marine law enforcement ship, the government ship, the ocean fishing vessel and so on, have been optimized or developed, and the batch orders of the upper many ship types have be placed. Besides this, the design and the order of a variety of many marine products, which possess the high-tech and high value-added, have more highlights.

Further Improve Localization Rate of Corollary Equipment. A batch of new products, which include various electronic intelligent low-speed diesels, the self-owned brand high-middle-speed diesel, the 10000-ton ocean surveillance ship power system, the domestic middle-low voltage electric 
propulsion system, the high temperature superconducting motor, the disc separator, the fuel oil (slip) supply system, the water sealed incineration system, the jack-up platform lifting device, the HDP3 dynamic positioning system, the large platform crane, the ballast water treatment system, the new generation Integrated Bridge System (IBS), the electronic sea chart display and information system, the ship autopilot and so on, have been successfully designed and manufactured, and some of these new products have been realized the industrialization or the trial-manufacture of some model machines has been accomplished. Over all, the localization rate of the corollary equipment of the ship and the marine equipment manufactured in china has been further improved.

Step of Resource Integration Becomes Quicker. Some enterprise groups and major shipbuilding areas actively carry out resource integration and optimize the industrial layout. In one side, multiple enterprise groups comprehensively optimize their internal resources, and integrate relevant units, and densify their coral units so that their brand influence and their market competitiveness is both improved. In the other side, multiple shipbuilding areas optimize the industrial layout, and promote the development of the characteristic and industrial base; They also strictly carry out the industry standards, and gradually eliminate the backward production capacity; They also encourage the leading enterprises annex and reorganize the medium-sized and small enterprise, the backward enterprise, the difficulty enterprise or the idle resources enterprise to carry out mergers and reorganizations, and encourage ship companies formed a strategic alliance.

\section{Some Problems in Development ${ }^{[3,4]}$}

Although it has accomplished great achievements, Chinese SI has the following problems.

Entirely Competitive Power Somewhat declines. Although Chinese ship enterprises have some advantages, which include the lower cost such as the lower labor cost and the lower raw material cost and the better nature condition that China has a long coast line which strides across four temperature zones and so on, than South Korea and Japan have, the whole competitiveness of Chinese SI has declined considering that advanced shipbuilding enterprises in South Korea and Japan continuously improve the capability of the design, the construction, the management and other aspects.

Industrial Center Ratio isn't high. From Table 1 it can be known that top ten enterprises in Chinese SI accounts for the $27.87 \%$ and that the Center Degree of Chinese SI is obviously lower compared with the $80 \%$, which is the Cumulative Ratio of the top five enterprises in South Korean SI.

Table 1 Center Degree of Chinese SI

\begin{tabular}{|c|c|c|c|c|}
\hline No. & Enterprise Name & $\begin{array}{l}\text { Adjusted Gross } \\
\text { Tonnage }\end{array}$ & Industrial Ratio & Cumulative Ratio \\
\hline 1 & SWS & 1168738 & $4.77 \%$ & $4.77 \%$ \\
\hline 2 & DSIC & 1163580 & $4.75 \%$ & $9.52 \%$ \\
\hline 3 & NCship & 756487 & $3.09 \%$ & $12.61 \%$ \\
\hline 4 & YZJship & 618658 & $2.53 \%$ & $15.14 \%$ \\
\hline 5 & HZ-shipgroup & 617430 & $2.52 \%$ & $17.66 \%$ \\
\hline 6 & RSHI & 600396 & $2.45 \%$ & $20.11 \%$ \\
\hline 7 & YZDAYANG & 527721 & $2.15 \%$ & $22.26 \%$ \\
\hline 8 & SSYRCS & 497798 & $2.03 \%$ & $24.30 \%$ \\
\hline 9 & JinHai HI & 444436 & $1.81 \%$ & $26.11 \%$ \\
\hline 10 & GSI & 430913 & $1.76 \%$ & $27.87 \%$ \\
\hline
\end{tabular}

Many Low-end Products Exist. The yield of Chinese SI in recent years is more than one of Japan SI and South Korea SI, but on the product structure, the high value added product of Chinese SI is less than the one of Japan SI and South Korea SI, and the middle-low-end products is more than the high-end products in Chinese SI, and these products, which include the conventional bulk, the conventional tanker and the conventional container ship, accounts for the percentage which is greater than the $60 \%$ and meantime is less than the $70 \%$ of Chinese SI, and meanwhile the order of these products, which include the high added value tanker, the LNG ship and the marine engineering equipment, is majorly got by Japan SI and South Korea SI. In a word, Chinese SI currently lies in the "low-end excess, high-end deficiency" dilemma compared with Japan SI and South Korea SI. 
Science and Technology Innovation Capacity Isn't Enough. In the aspect of the development of ship type and the design and research of ship, most of the ships designed and built by Chinese own ability are these ships, which are below 150000-ton ones and include the bulk carrier, the oil ship and the small and medium sized container ships and so on. At the same time, compared with the advanced world level in the design technology and the design mean, the overall level of Chinese SI is lower, there but also are other deficiency such as the longer design cycle, the lower independent innovation ability and so on.

Some Enterprises Have a Difficulty in Transformation and Upgrading. Presently, facing the situation that the requirements of the new product design is more and the difficulty of the new product design is higher and the preparation cycle of the production technology is enough and so on, some ship enterprises can't keep pace with the adjustment and optimization of the SI structure, and Chinese SI also gradually exposes some problems, which include the less technology strength, the worse R\&D capability, the loose production management, the frequenter modification of the design process and so on, so that the risk of new ship construction increases and the transformation and upgrading becomes beset with difficulties.

Talented Persons of Chinese SI are Lack. In recent years, in one side, Chinese SI talented person training is lagging behind the rapid expansion of the shipbuilding enterprise. In another side, state-owned enterprises, foreign-funded enterprises and private enterprises is fighting over the talented person, the technical talented person and the skilled production workers. Therefore, the lack of the talented person is very obvious in Chinese SI and especially the shortage of high-end technical talented person and skilled workers who restrict the development of Chinese SI is more common.

\section{Development strategy}

According to the development situation of Chinese SI and based on the development trend of the economy at home and abroad, Chinese SI should implement the following development strategy.

Further Speed up Adjustment and Upgrading of Industrial Structure. Chinese SI should quicken transferring the development as the main line, improve the development quality and effectiveness as the center, strengthen the research of the key common technology and the process technology, develop more green environmental protection ships and high technological ships and ocean engineering equipment suit for the market demand, promote the enterprise merger and reorganize and promote resources be integrated, optimize industrial organization structure, actively digest excess capacity and focus on the adjustment and upgrading of industrial structure.

Thoroughly Carry out Strategy of Going to Globe. The opportune moment or the occasion when Chinese SI build the shipbuilding plant with direct investment overseas and in the advantage of the low cost is not mature, while it is an important task faced by the large enterprise group in the Chinese SI that these enterprises build the R\&D center and the market and maintenance net and the manufacturing base for the direction that they gain the technology-brand-human resource and improve the marketing level and press close to the overseas markets through many means such as a self-building, a merging, a joint venture and a cooperation.

Pay Close Attention to Adjustment and Development of Medium-sized and Small Enterprises. Relevant departments at all levels should pay close attention to and classified guide the adjustment and development of the medium-sized and small enterprises. For example, in one side, the enterprises, which possess a certain strength, should be directed to develop to become the ones which have the specialty-essence-uniqueness-newness supported from different aspects such as the product research, the finance and taxation and the talent introduction; on another side, the enterprises, which have difficulties in the daily production, should be directed to decisively adjusted and can be helped to resolve problems in the adjustment.

More Quickly Eliminate Backward Production Capacity and Defuse Excess Production Capacity. Chinese SI should actively grasp opportunity of the structure adjustment and the transformation and upgrading of the SI, and start with optimizing the productivity layout, and make the resource integration as vinculum, and make improving the coral competitive power of the SI as 
the purpose, and vigorously promote the merger and reorganization and the optimization and adjustment and the dissolving excess production capacity, and actively carry out the science research innovation, the technical reconstruction or the production process flow improvement in order to reuse the production capacity which is inefficient but conforming to the development trend of the SI, and quicken increase the environmental protection standards, the energy saving standards, the technical standards and other standards to eliminate the production capacity with the backward technology and the inefficiency.

Strengthen Personnel Training and Introduction Exchange. Chinese SI should establish and perfect the personnel training and introduction mechanism, and strengthen the safeguard of the training and introduction of the personnel, and promote the construction of the talent cultivation and the talent base as a whole plan, and actively introduce a batch of outstanding professionals of the research and development, the design, the manufacture, the management and so on in the high-tech ships, the special ships, the Marine engineering equipment and other related areas, and focus on cultivating the upper professional backbone talented person and the talented person echelon in order to provide the powerful human resources guarantee for the transformation and development of Chinese SI.

\section{References}

[1] Shan Shi-ying. Analyze on International Status and Development State of China's Ship-building Industry [J]. Jiangsu Commercial Forum, 2013, 09:27-30.

[2] Jiang Zhi-zhou. Internationally Standardizing Shipping Industry : Breakout [J]. Quality and Standardization, 2013, 07:21-23.

[3] Wang Zhe. When Will Chinese Shipping Industry Overwinter [J]. China Customs, 2013, 06:56-57.

[4] Zhan Rui-wan, Tai Yang-sheng. Excess Production Capacity Appears in Chinese Shipping Industry [J]. Pearl River Water Transport, 2012, 20:46-49. 